\title{
9 Three Ways of Resisting Essentialism about Natural Kinds
}

\author{
Bence Nanay
}

\section{Essentialism about Natural Kinds}

Essentialism about natural kinds has three tenets. The first tenet is that all and only members of a natural kind have some essential properties. The second tenet is that these essential properties play a causal role. The third tenet is that they are explanatorily relevant. I examine the prospects of questioning these tenets and point out that arguing against the first and the second tenets of kind-essentialism would involve taking part in some of the grand debates of philosophy. But, at least if we restrict the scope of the discussion to the biological domain, the third tenet of kindessentialism could be questioned more successfully.

It is not an easy task to pin down what is meant by essentialism about natural kinds (Putnam 1975; Kripke 1980). First, one can be essentialist about individuals and about kinds. I will not say anything here about essentialism regarding individuals. Maybe, as Kripke claims, specific individuals have essential properties, maybe not (on this important and complex question, see, for example, Robertson 1998; Hawthorne and Gendler 2000; Matthen 2003). Essentialism about individuals is logically independent from essentialism about kinds (see also Okasha 2002, 192). The question I am interested in is whether natural kinds have essential properties.

Second, there are a number of potential definitions for essentialism about kinds. As I intend to argue against essentialism, I will use the most general of these. Richard Boyd identified a widespread and fairly strong version of essentialism, according to which natural kinds "must possess definitional essences that define them in terms of necessary and sufficient, intrinsic, unchanging, ahistorical properties" (Boyd 1999, 146). Essential properties in, say, chemistry may all be intrinsic, unchanging, and ahistorical. But it is not clear that all essential properties need to 
satisfy any of these three requirements. In fact, a rather easy way of arguing against essentialism about at least some natural kinds-namely, biological kinds-is to point out that biological properties are extrinsic, historical, and change over time since biological entities are evolving over time. But it is unlikely that arguments of this kind will defeat essentialism about biological, natural kinds. A new wave of biological essentialists all seek to specify essential properties of biological kinds that are extrinsic, and yet are neither unchanging nor ahistorical. ${ }^{1}$ The simple argument from the observation that biological entities are evolving over time cannot be used to argue against these versions of biological essentialism.

Thus, if we want a target that is worth arguing against, we need to weaken this strong definition of essentialism. As most of the new essentialists, I am also happy to go along with David Hull's characterization, according to which "each species is distinguished by one set of essential characteristics. The possession of each essential character is necessary for membership in the species, and the possession of all the essential characters sufficient" $(1994,313)$. I will use Hull's definition as my starting point for characterizing kind-essentialism in what follows. ${ }^{2}$

Third, essentialism about kinds is a complex thesis that goes beyond the simple claim that there are some properties that all and only members of a natural kind have in all possible worlds. Marc Ereshefsky specified three tenets of any version of essentialism about kinds:

One tenet is that all and only the members of a kind have a common essence. A second tenet is that the essence of a kind is responsible for the traits typically associated with the members of that kind. For example, gold's atomic structure is responsible for gold's disposition to melt at certain temperatures. Third, knowing a kind's essence helps us explain and predict those properties typically associated with a kind. (Ereshefsky 2007, sec. 2.1)

Most philosophers who, like Ereshefsky, argue against essentialism, only consider the first tenet. Proponents of essentialism also tend to be concerned only with this first tenet. In contrast, I would like to focus on the second and especially the third tenet.

My claim is that questioning the second or third tenets may be a more promising way of resisting kind-essentialism. In short, a promising and so far almost completely unexplored anti-essentialist strategy would be to say that even if it turns out that "all and only the members of a kind have a common essence," this essence is unlikely to play any significant causal or explanatory role. 
The plan for the essay is simple: I go through the three tenets of essentialism and explore which of them would be the easiest to question. My final response will be that arguing against the first and the second tenets of kind-essentialism would involve taking part in some of the grand debates of philosophy. But at least if we restrict the scope of the discussion to the biological domain, the third tenet of kind-essentialism could be questioned more successfully.

\section{Questioning the First Tenet: All and Only the Members of a Kind Have a Common Essence}

I am not sure that the question whether "all and only the members of a kind have a common essence" can be settled. A rather straightforward way of arguing against the first tenet would be to use some general metaphysical considerations. The first tenet of kind-essentialism states that all and only members of a kind have a certain essential property: an essence. The crucial point is that 'property' here means "property-type." The set of essential properties that defines natural kinds is a set of essential property-types. The instantiation of each essential property-type is necessary for membership in the natural kind and the instantiation of all the essential property-types is sufficient. I pause to make the distinction between property-types and property-instances explicit.

The term 'property' is ambiguous. It can mean universals: properties that can be present in two (or more) distinct individuals at the same time. But it can also mean tropes: abstract particulars that are logically incapable of being present in two (or more) distinct individuals at the same time (Williams 1953; Campbell 1981, 1990; Schaffer 2001; Simons 1994; Sanford manuscript).

Suppose that the color of my neighbor's black car and my black car are indistinguishable. They still have different tropes. The blackness trope of my car is different from the blackness trope of my neighbor's car. These two tropes are similar but numerically distinct. Thus, the blackness of my car and the blackness of my neighbor's car are different properties.

If, in contrast, we interpret properties as universals-or as I will refer to them, as property-types - then the two cars instantiate the very same property-type: blackness. Thus, depending on which notion of property we talk about, we have to give different answers to the question about whether the color-property of the two cars is the same or different. If by 'property' we mean "trope," then my car has a different (but similar) color-property-that is, color-trope-from my neighbor's. If, however, by 
'property' we mean "property-type," then my car has the very same property-that is, property-type-as my neighbor's.

In the light of this distinction, the first tenet of essentialism about natural kinds can be broken down to the conjunction of two claims: (a) property-types exist, and (b) some property-types are essential propertytypes. Many anti-essentialist arguments question (b) while accepting (a) (e.g., Hull 1986, as far as the biological domain is concerned). I will focus on the more radical strategy of questioning (a) because, in sections 5 and 6 , I will argue that (at least in the domain of biology) a strategy quite similar to this may be used in order to argue not against the first, but against the third tenet of essentialism about natural kinds.

As the first tenet of kind-essentialism states that all and only members of a kind have a certain essential property-type, a straightforward way of arguing against this tenet is to question (a): to show that property-types do not exist and hence, a fortiori, essential property-types do not exist either. In other words, if we accept a version of nominalism, then there is a simple way of resisting any version of essentialism about natural kinds. If only particulars exist and property-types do not, then how could we even formulate essentialism about natural kinds?

This would be a simple and straightforward argument against essentialism about natural kinds, but it is not clear that we have any reason to accept its main premise: that property-types do not exist. The grand debate between nominalism and realism is one of the oldest in philosophy and it has definitely not been resolved. Taking for granted the premise that there are no property-types would significantly weaken an anti-essentialist argument in the eyes of those who are not fully convinced by nominalist considerations.

Further, we need to be a bit more careful about what version of trope nominalism the anti-essentialist strategy I outlined above needs to endorse. Many trope-nominalist accounts define property-types as sets or resemblance-classes of tropes. Thus, according to these accounts, although the existence of property-types in some sense reduces to the existence of tropes (and, as a result, in some sense they are not "real"), they do have mindindependent existence: there is a fact of the matter about whether a trope subsumes under a certain set or resemblance-class.

The version of trope nominalism that would be needed to question (a) needs to be more radical than this: it cannot allow for there being a fact of the matter about whether a trope subsumes under a certain set or resemblance-class. If it did allow for this, then the essentialist view could be rephrased in terms of "essential" sets or "essential" resemblance-classes 
of tropes. In order to block (a), the trope nominalist needs to claim that property-types are just our ways of grouping tropes: they do not have mind-independent existence (Nanay 2009, 2010a, 2011). But this is an even more controversial assumption for an anti-essentialist argument to rely on.

But even if such a version of trope nominalism is a dubious premise to build our argument on, perhaps if we restrict the scope of our argument to the biological domain then the first tenet could be questioned successfully.

\section{Questioning the First Tenet of Kind-Essentialism in the Biological Domain}

Biology has always been considered to be a problem case for essentialism or at least a potential exemption. According to the traditional "antiessentialist consensus" (Okasha 2002, 195; Walsh 2006, 325) among biologists and philosophers of biology, at least regarding biological kinds, essentialism is false (Dupré 1993, 2002; Hull 1965; Ghiselin 1974; Hacking 2007). Putnam and Kripke may be right about chemical kinds, but biological kinds do not have (and cannot have) any essential properties (Wilkerson 1995; Ellis 2001).

But over the last several years, more and more philosophers have argued for a version of essentialism about biological kinds. Paul Griffiths, for example, argues that biological kinds have "essential relational properties" not essential intrinsic properties-and claims that if we accept that essential properties can be relational, then all the traditional considerations against essentialism about biological kinds lose their appeal (Griffiths 1999). (For a similar claim, see Okasha 2002. The idea of using relational properties for defining biological kinds, not necessarily in an essentialist manner, comes from Matthen 1998; Millikan 1999; and Elder 1995.) Denis Walsh goes even further and claims that "recent evolutionary developmental biology provides compelling evidence" for essentialism $(2006,425)$.

In order to assess the merits of this new wave of essentialism about biological kinds, the traditional anti-essentialist arguments need to be reevaluated. There are anti-essentialist arguments that prove to be inconclusive. One such argument concerning essentialism about biological kinds, is the following (Hull 1965; for objections, see Sober 1980, 356; Okasha 2002, 195-196; Walsh 2006, 431). According to evolutionary theory, the present species have evolved from ancestral ones. Thus, species cannot have essences, as they are clearly capable of changing. This 
argument may be taken to jeopardize a version of essentialism, one that takes kinds to be unchangeable, but it does not apply in the case of other versions of essentialism.

Some other anti-essentialist considerations are not obviously inconclusive. The most important of these are based on the concept of "population thinking." Since using population thinking to argue against essentialism shares some important features with my own argument against the third tenet of essentialism in sections 5 and 6, I will spend some time trying to understand what population thinking is supposed to mean, and why it is assumed to be an effective weapon in the fight against essentialism.

Population thinking has traditionally been the main consideration against essentialism about biological kinds. The strategy of philosophers with anti-essentialist convictions about biology has been to point out that since population thinking implies anti-essentialism and population thinking is the right way of thinking about biology, we have to be anti-essentialist about biology.

This strategy can be attacked at two points. First, the essentialist could argue that population thinking is not the right attitude to take toward the biological domain. No philosophers or biologists seem to take this route. The second way of attacking the anti-essentialist strategy would be to deny that population thinking implies anti-essentialism. And in fact, with the rise of contemporary attempts to bring essentialism back in the domain of biology, it has been repeatedly argued that population thinking does not exclude essentialism. Thus, one can endorse population thinking and still agree with Putnam and Kripke about the essential properties of biological kinds.

All of the recent attempts to resurrect essentialism about biological kinds find it important to show that their version of essentialism is consistent with population thinking (Walsh 2006, 432-433; Okasha 2002, 195-196). Paul Griffiths says explicitly that "it would be quite consistent to be a Darwinian [population-thinking] essentialist, given the right choice of essential properties" (Griffiths 1999, 210). Or, more explicitly: "Population thinking excludes essential intrinsic properties, but it does not exclude essential relational properties" (ibid.; cf. Okasha 2002). Whether these attempts to carve out an essentialist way of construing population thinking succeed depends on the way we interpret population thinking. Conversely, whether population thinking really gives us some reason to have doubts about essentialism about biological kinds also depends on the way we interpret population thinking. As both proponents and opponents of essentialism about biological kinds seem to rely on population thinking in 
their arguments, it is important to examine what population thinking is and what it implies.

My claim is that Ernst Mayr's influential idea of what makes the biological domain special, the idea of "population thinking," could, and should, be interpreted as a version of trope nominalism (Nanay 2010a). Here is Mayr's characterization of population thinking from 1959: "Individuals, or any kind of organic entities, form populations of which we can determine only the arithmetic mean and the statistics of variation. Averages are merely statistical abstractions; only the individuals of which the populations are composed have reality" (Mayr 1959, 326). Mayr contrasts population thinking with typological thinking, according to which "there are a limited number of fixed, unchangeable 'ideas' underlying the observed variability, with the eidos (idea) being the only thing that is fixed and real, while the observed variability has no ... reality" (ibid.). The contrast Mayr makes is a very sharp one: population thinking and typological thinking are exclusive of each other (ibid., 326-327).

Mayr's distinction between typological and population thinking may appear straightforward, but in fact it could be (and has been) interpreted in at least two ways. First, population thinking could be interpreted as an ontological claim about entities: only the individual is real, everything else is abstraction. There are various problems with this reading. If only the individual is real, then populations and species should be thought of as groups of individuals which, as groups, lack reality themselves. This would make much of post-Darwinian biology nonsensical from the population thinker's point of view. As Elliott Sober says:

If [as Mayr claims] "only the individuals of which the populations are composed have reality," it would appear that much of population biology has its head in the clouds. The Lotka-Volterra equations, for example, describe the interactions of predator and prey populations. Presumably, population thinking, properly so called, must allow that there is something real over and above individual organisms. [It does not] embody a resolute and ontologically austere focus on individual organisms alone. (Sober 1980, 352)

Even more problematic for this reading is the fact that Mayr himself is certainly not nominalist about populations and species (Mayr 1942, 120; Mayr 1963, 19). His dictum that "only the individuals . . have reality" seems to flatly contradict his famous "biological species concept" which indeed attributes reality to populations and species. It is tempting to resolve this seeming contradiction by dismissing Mayr's claim about the importance of the individual in evolution as an exaggeration or even as "rather silly metaphysics" (Ariew 2008, 2). ${ }^{3}$ 
Elliott Sober chooses this route when he says that "describing a single individual is as theoretically peripheral to a populationist as describing the motion of a single molecule is to the kinetic theory of gases. In this important sense, population thinking involves ignoring individuals" (Sober 1980, 370). The conclusion he draws is that "population thinking endows individual organisms with more reality and with less reality than typological thinking attributes to them" (Sober 1980, 371).

This conclusion prompted some to be "a little confused about which one, individuals or populations, are real" (Ariew 2008, 8). It also opened up the concept of population thinking to many diverging interpretations, some of which seems to contradict Mayr's original claims (Walsh 2006, 432-433; Griffiths 1999, 209-210).

I argue that population thinking is an ontological claim about properties and not about entities. It is indeed a version of nominalism. However, it is not nominalism about entities, but about properties. In other words, Mayr advocated a version of trope nominalism: for the population thinker, only the property-instances, that is, tropes, are real. Property-types are not real.

We have to be careful when formulating this claim. The population thinker presumably would not deny that groups of individual organisms do have properties and that these properties are real. A population of 431 geese has the property of having the population size of 431 , for example, and this property seems very real indeed. The distinction I am making (and the distinction I believe Mayr was making) is not one between the properties of individuals and the properties of populations. Rather, it is between individual property-instances (or tropes) and property-types (or universals) that can be instantiated in many different entities. In short, the population thinker can acknowledge the existence of populations and species. These entities are real in the same way as individuals are real. And all of these entities have very real property-instances or tropes. What the population thinker denies is that there are property-types.

My claim is that Mayr's provocative statement, according to which "averages are merely statistical abstractions; only the individuals of which the populations are composed have reality" should be read as "propertytypes are merely statistical abstractions; only the tropes of individuals (or of populations) have reality." Mayr's population thinking is a version of trope nominalism (see esp. Mayr 1959, 326, where he talks about the uniqueness of features, i.e., properties, and not the uniqueness of individual entities). ${ }^{4}$

We can now put together an argument against the first tenet of kindessentialism in the biological domain: (i) Population thinking is the right 
way of thinking about the biological domain. (ii) Population thinking implies trope nominalism. (iii) Trope nominalism implies anti-essentialism about biological kinds. I have presented some considerations in favor of (ii) and (iii), but as yet have said nothing that would make us accept (i): that population thinking, that is, trope nominalism, would be the right way of thinking about the biological domain. And I am not sure what argument could be given in favor of (i), besides appealing to the authority of Ernst Mayr-without this premise, the argument collapses.

In section 6, I will give an argument for the claim that biological property-types play no explanatory role in evolutionary explanations. Could we use this argument to establish (i)? Mayr's claim is much stronger than mine, as he denies the reality (not merely the explanatory relevance) of biological property-types: he claims that they are merely our statistical abstractions.

Yet, depending on one's meta-metaphysical convictions, there may not be such a huge difference between these two versions of trope nominalism: Mayr's stronger version and the weaker "explanatory trope nominalism" I will argue for below. One could, after all, use the weaker claim that biological property-types are explanatorily superfluous and, with the help of the principle of parsimony, conclude that we have no reason to postulate their existence.

But not everyone will find this last step unproblematic, and I do not want to argue that it is unproblematic. If someone believes that we can infer from the fact that something is explanatorily superfluous that it does not exist (as Mayr may have believed), then she will not find the distinction between my "explanatory trope nominalism" and Mayr's population thinking a very interesting one. She will probably not find the distinction between the first and the third tenet of kind-essentialism a meaningful one either. But if someone does not believe that explanatory irrelevance implies non-existence, then she will still have no reason to accept (i) and hence to accept the population-thinking inspired rejection of the first tenet of essentialism about biological kinds.

The argument I considered in this section was unsuccessful in the end. But I will use its conceptual framework in the hopefully more successful argument against the third tenet of kind-essentialism, in sections 5 and 6 .

\section{Questioning the Second Tenet: Causal Responsibility}

The second tenet of kind-essentialism is about causal responsibility. As Ereshefsky says, "a kind's essence causes the other properties associated with that kind. The essence of the natural kind gold, for example, is gold's 
atomic structure. . . the atomic structure of gold causes pieces of gold to have the properties associated with that kind, such as dissolving in certain acids and conducting electricity" (forthcoming, 1).

What we say about this second tenet depends on what we say about the relata and properties of (singular) causation. If one holds that propertytypes play a role in (singular) causation, then the second tenet of essentialism remains unscratched. But if one holds that property-types play no causal role-maybe because no properties play any causal role (Davidson 1967,1970 ), or maybe because only property-instances (or tropes) play any causal role (Ehring 1997; Nanay 2009)—then we have reason to doubt the second tenet. But let us go through these considerations more slowly.

The question is whether property-types play any role in causation. The first clarification we need to make when answering this question is whether it is about general or singular causation. Property-types play a clear and important role in general causal claims. If Fs cause Gs, then there is a property, in virtue of which Fs cause Gs: a property all Fs have in common (that is, a property-type all Fs have an instantiation of) and that, presumably, can account for why Fs cause Gs. But it is unclear whether property-types play a role in singular causation, and it could be argued that questions about causal relevance are questions about singular, not general, causation.

There are two ways in which property-types can play a causal role. First, they may be part of what specifies the relata of causation. It is not clear what the relata of causation are. They may be events (Davidson 1967), facts (Mellor 1995), states of affairs (Armstrong 1997) or maybe tropes (Ehring 1997). Facts (or Kimian events) are specified in terms of property-types. Thus, if we accept that these are the relata of causation, then property-types will be causally relevant. But if we hold that the relata of causation are Davidsonian events or tropes, then property-types play no role in the specification of the relata of causation. Thus, we have no prima facie reason to accept that they are causally relevant.

But even if we take (Davidsonian) events to be the relata of causation, a further question arises: what is it in virtue of which one event causes another? First, the obvious answer would be that an event causes another event in virtue of having an instantiation of a property-type: the sleeping pill I took last night made me fall asleep in virtue of some chemical property-type it had an instantiation of. If we accept this answer, then property-types will be very relevant causally.

But there are other ways of answering this "in virtue" question. Donald Davidson famously denied that events cause other events in virtue of any 
properties. As he memorably said: "If causal relations and causal powers inhere in particular events and objects, then the way those events and objects are described, and the properties we happen to employ to pick them out or characterize them, cannot affect what they cause. Naming the American invasion of Panama 'Operation Just Cause' does not alter the consequences of the event" (Davidson 1993, 8). In other words, properties play no role in causal relations-although they may be very important in causal explanations. Another, less radical, way of denying that events cause other events in virtue of having instantiations of certain property-types would be to say that events cause other events in virtue of having tropes. Properties, if what we mean by that is tropes, do play an important role in causation: events cause other events in virtue of them. But property-types do not play any role (Robb 1997; Nanay 2009).

If we accept the Davidsonian or the trope answer to the "in virtue" question, then we can conclude that property-types are not causally relevant. But if property-types are not causally relevant, then essential property-types are not causally relevant either. But the second tenet of essentialism was that essences-that is, essential property-types-must be causally relevant. So, as in the case of the first tenet, we have a simple argument against kind-essentialism.

Note, however, that this argument rests on three heavily contested premises about the nature of causation; in order to run this argument, we need to make three important assumptions. First, we need to take singular, and not general, causation to be where causal relevance lies. Second, we need to take the relata of causation to be (Davidsonian) events (or tropes). And finally, we need to hold that events cause other events in virtue of having tropes (and not in virtue of having instantiations of propertytypes), or we need to endorse a Davidsonian view on the properties of causation. Few people hold all of these premises. Hence, as in the case of the argument against the first tenet of kind-essentialism, this argument is also based on premises concerning the nature of causal relations that many would question from the start.

\section{Questioning the Third Tenet: Explanatory Relevance}

The third tenet of kind-essentialism was the following: "Knowing the essence of a kind ... allows us to predict and explain the properties associated with the members of a kind. For instance, the atomic structure of gold provides the basis for explaining why gold conducts electricity, and it allows us to predict that a particular chunk of gold will conduct electricity" 
(Ereshefsky, forthcoming, 1). Or as Philip Kitcher puts it, "natural kinds are distinguished by some special underlying feature that explains the behavior of members of this kind-like atomic number, for example, in the case of the elements" (Kitcher 2007, 294; Dupré 2002, 176-181; Wilson et al. forthcoming). (See Platts 1983 for a classic summary and Okasha 2002, 203 for some critical remarks.) If we can show that this third tenet of essentialism is unjustified, then we have a good way of arguing against essentialism per se.

As in the case of the first and second tenets, I find it unlikely that we can give a general argument against the third tenet-any such argument would need to presuppose a rather specific and, as a result, heavily contested theory of explanation. But I do think that at least as far as the biological domain is concerned, we are in a good position to question the third tenet.

We have seen that it is unlikely that we would find some strong reason to reject the very idea that biological property-types are "real." But we may be able to find an argument for the claim that biological property-types play no explanatory role in biology. They may be "real" and exist independently of us, but if they are explanatorily superfluous, this is enough to undermine the third tenet of essentialism about biological kinds. I will give an argument in favor of this claim in the next section.

\section{Questioning the Third Tenet of Kind-Essentialism in the Biological Domain}

My claim is that property-types are explanatorily superfluous in evolutionary explanations. All the explanatory work is done by property-instances. This claim needs to be clarified and qualified at a number of points. First, I want to remain silent about whether property-types play any explanatory role in non-biological, non-evolutionary explanations. Maybe they do. When we are trying to explain why a certain gold sample melts at $1,948^{\circ} \mathrm{F}$, we can explain this by referring to a property-type all gold samples have an instantiation of (maybe the property-type of having a certain atomic structure). In this explanation, we have a property-type as part of the explanans. The property-type may or may not be causally relevant, but it is explanatorily relevant. My claim is that this is not the case in evolutionary explanations, where the explanans refers only to property-instances.

Second, it is important to note that I do not claim that using tropes instead of property-types in the metaphysical framework increases the 
explanatory power of evolutionary theory. After all, it has been argued, convincingly, that statements about tropes and statements about instantiations of property-types are notional variants: one can always be rephrased in terms of the other (Daly 1997). All I claim is that adding biological property-types to a trope nominalist metaphysical framework does not increase the explanatory power of evolutionary theory. Hence, propertytypes are explanatorily superfluous.

I said that in the domain of biology, property-types do not do any explanatory work and property-instances do all the work. An important clarification about this claim: I talked about the biological domain, biological property-types and biological tropes. But it is not clear where the boundaries of the biological domain lie. Is DNA part of the biological domain or is it already part of the domain of chemistry? Also, there are many different kinds of explanation (Van Fraassen 1980). Saying that property-types play no role in any of them would be a difficult claim to argue for. So I will restrict the scope of my claim in the following manner: property-types play no role in evolutionary explanations. When I talk about the explanatory role (or lack thereof) biological property-types play, what I mean is explanatory role in an evolutionary explanation. Biological kinds are evolved kinds and biological entities are evolved entities. Thus, if a property-type is supposed to play some explanatory role in biology, like the atomic structure of gold explains why it melts at certain temperature, then, as the explanation of the properties of evolved entities is an evolutionary explanation, this means that this property-type is supposed to play at least some role in evolutionary explanations. I will attempt to show that this is not so: no property-type plays any role in evolutionary explanations. ${ }^{5}$

Let us go back to what the third tenet of essentialism entails. Ereshefsky's example is that "the atomic structure of gold provides the basis for explaining why gold conducts electricity, and it allows us to predict that a particular chunk of gold will conduct electricity" (Ereshefsky, forthcoming, p. 1). Philip Kitcher uses a similar example: "natural kinds are distinguished by some special underlying feature that explains the behavior of members of this kind - like atomic number, for example, in the case of the elements" (Kitcher 2007, p. 294). They both take their examples from chemistry. But what would be the equivalent of these claims in biology?

What is important from our point of view is that both Ereshefsky and Kitcher talks about the explanation of the behavior of a particular token member of the kind (or a token chunk of gold). Hence, in the domain of biology, an essential property would need to be able to explain why specific 
token organisms have the traits they do. And, luckily, a lot has been written about exactly this kind of explanation.

In fact, one of the most important recent debates in philosophy of biology is about whether natural selection can explain why specific organisms have the traits they have. The view that selection can play a role in explaining why organisms have the traits they have, has been defended by Karen Neander (1995a,b; see also Millikan 1990; Nanay 2005, 2010b; Matthen 1999). On the other side of the trench the central figure is Elliott Sober (1984a, 1995; see also Walsh 1998; Dretske 1988, 1990; Pust 2001; Lewens 2001; Cummins 1975; and Stegmann 2010).

Sober claims that selection is a negative force: it does not create; it only destroys (Sober 1984a, chapter 5). Random mutations create a variety of traits (or genetic plans) and selection eliminates some of these, but the explanation of the traits of one of these individuals is provided by random mutation and inheritance (and some developmental factors), not by the elimination process. Selection can explain why certain individuals were eliminated and it may also explain why a trait is present (or widespread) in a population, but it cannot explain the traits of specific individuals that were not eliminated.

Karen Neander argues against the validity of this argument, at least as far as cumulative selection is concerned (Neander 1995a). After a couple of rounds of exchanges without any sign of rapprochement, one gets the sense that there is some sort of miscommunication between Neander and Sober. One gets the sense that the opponents and the advocates of this argument may not mean the same by the term 'selection'.

My aim here is not to decide who is right in this debate (I attempted to do this in Nanay 2005 and Nanay 2010b). My aim is to show that regardless of which of these two views about the explanatory power of selection we accept, we can conclude that property-types do not play any role in explaining why token organisms have the token traits they have.

Take Sober's position first. He has argued repeatedly that the theory of natural selection can only be formulated with the help of property-types, that is, property types play a very important role in the theory of natural selection (most explicitly in Sober 1981, but also in Sober 1980 and Sober 1984). As he says in a paper co-authored with Richard Lewontin: "selection theory is about genotypes not genotokens" (Sober-Lewontin 1982, p. 172; see also Sober-Lewontin 1983, p. 649). And even more explicitly: "to understand what it means to talk about the selection of genes, organisms, or groups, one must quantify over properties" (Sober 1981, p. 162). 
This may sound like bad news for my claim that property-types do not play a role in explaining why token organisms have the traits they have, but remember that Sober maintains that what explains why token organisms have the traits they have is not selection. What does this explanatory work, according to Sober is random mutation and inheritance (and, presumably, some developmental factors) (Sober 1995). And mutation, inheritance and development should be taken to be token phenomena here: the mutation in a token ancestor of the organism, inheritance from one token organism to another and the developmental processes of the organism are all processes that operate on token traits. In short, if we take Sober's side in the grand debate about the explanatory power of selection, we can conclude that property-types do not play any role in explaining why specific token organisms have the traits they have.

But what if we take Neander's side, who claims that cumulative selection does explain why specific token organisms have the traits they have? Here, the answer is more complicated. First, it is important to note that Neander's claim is that cumulative selection can explain why specific token organisms have the traits they have. And here is what she means by cumulative selection: what makes cumulative selection cumulative: that "the probable outcome of future [rounds of selection] depends on the results of previous [rounds of selection] (Neander 1995b, p. 584).

It could be pointed out that this conception is much stronger than what Sober means by cumulative selection (most famously in his discussion of the 'selection toy' [Sober 1984, p. 99])—and this may explain the miscommunication between Sober and Neander. But what is important from the point of view of the present argument is that Neander's way of interpreting cumulative selection does not presuppose any talk of property-types. Take the (uniparental) organism, $a$, whose neck is $12 \mathrm{~cm}$ long. It has two offspring, $b$ and $c$, with 14 and $10 \mathrm{~cm}$ long neck, respectively. As organism $b$ gets to reach branches with leaves that organism $c$ cannot, it gets to survive, whereas organism $c$ starves to death. Organism $b$ also has two offspring, $d$ and $e$, with 16 and $12 \mathrm{~cm}$ long neck and $d$ survives, whereas $e$ starves to death. This is cumulative selection in Neander's sense: the traits of the organisms change from generation to generation, not just the trait frequencies. Further, the fact that $b$ survives and $c$ dies influences neck size of the next generation. As it is $b$ (and not $c$ ) who gets to survive, the starting point for the variation in neck size for the next generation is $14 \mathrm{~cm}$ (and not $10 \mathrm{~cm}$ ).

This way of thinking about cumulative selection explains the token traits of specific organisms in terms of past selection of token traits. It 
explains why organism $d$ has such a long neck by pointing out that $d$ 's parent, $b$ had longer neck than $c$ and got to survive as a result. The difference between traits that are responsible for the death of some organisms and the survival of others is a difference between token traits of specific organisms (i.e., the difference between $b^{\prime}$ s $14 \mathrm{~cm}$ long neck and $c$ 's $10 \mathrm{~cm}$ long neck) and not a difference between abstract trait types.

A possible objection: Couldn't we refer to the trait tokens of specific organisms as instantiations of a trait type, say, the trait type of being 12 $\mathrm{cm}$ long? We could, but this would have very problematic consequences. An instantiation of the trait type of being $12 \mathrm{~cm}$ long was responsible for $a$ 's survival, but another instantiation of the same trait type is responsible for $e$ 's death (whose neck is also $12 \mathrm{~cm}$ long). Hence, it would be problematic to take what is responsible for the death or survival of organisms to be trait types, because instantiations of the very same trait type are responsible for death in one generation and survival in another. What is responsible for the death of $e$ and the survival of $a$ are not trait types, but trait tokens (see Nanay 2010a for a more detailed version of this argument as well as for some clarifications that I could not include here).

But then this way of thinking about selection does not appeal to any property-types. Hence, if selection, interpreted in this way, can explain why specific token organisms are the way they are, then it is still true that property-types do not explain why specific token organisms are the way they are. Regardless of which side of the debate over the explanatory power of selection we choose, it remains true that property-types do not play any explanatory role in explaining why specific token organisms are the way they are.

Of course not all evolutionary explanations are selective explanations. I was focusing on the explanatory role of selection above, but similar arguments could be given with regards to non-selective evolutionary processes, such as the founding effect. Like selection, founding effect can also be fully accounted for by individual level processes, such as the specific evolutionary history of specific organism, without appealing to any trait types. Thus, we have no reason to attribute any explanatory role to any property-type. $^{6}$

My conclusion is then that even if we do not have any reason to deny that there may be some properties, that is, property-types, that all and only members of a biological kind possess in all possible worlds, if the argument I presented in this section is correct, we need to conclude that these properties, that is, property-types, although they may exist, play no explanatory role for the simple reason that no property-type plays any explanatory role 
in the biological domain. Thus, essentialism about biological kinds fails not because of the first (or the second), but because of the third tenet. The problem is not with the existence of essential property-types, but with their explanatory role. ${ }^{7}$

The conclusion, then, is that we should be skeptical about the third tenet of kind-essentialism in the biological domain. Putnam and Kripke may be right about chemical kinds, but essentialism is unlikely to be the correct view about biological kinds.

\section{Acknowledgments}

I am grateful for comments by Peter Godfrey-Smith, Jason Rhein, Karen Neander, David Sanford, Marc Lange, David Papineau, Roberta Balarin, James Young, and Jeff Foss on an earlier version of this paper. I presented this paper at the Inland Northwest Philosophy Conference and at the British Columbia Philosophy Conference. I am grateful for my commentators as well as the audiences. This paper grew out of the discussion at my $\mathrm{PhD}$ seminar on scientific realism at Syracuse University in fall 2007. I'm also grateful for the feedback of my students in my seminar on natural kinds in fall 2008, and for the tough criticism from my colleagues at the mysterious SPDMBABWS Society.

\section{Notes}

1. Griffiths 1999; Boyd 1999; Okasha 2002. See Walsh 2006 and Devitt 2008 for a different way of resurrecting essentialism about natural kinds, and Ereshefsky (Manuscript) for objections to both projects.

2. There may be ways of weakening essentialism even more by denying that essentialism implies that all and only the members of a kind must have a kind-specific essence (Boyd 1999). I will say a bit more, in sections 5 and 6, about the relevance to such accounts of the argument I present in this paper.

3. It is worth noting that one way of defending Mayr's position from worries of this kind would be to embrace the recently popular view that populations are individuals and members of populations are the parts of this individual (Ghiselin 1974; Hull 1978).

4. It is also worth noting that as Mayr considers property-types as "merely statistical abstractions," he denies that they have mind-independent existence-they do not have "reality," as he puts it. So Mayr's version of trope nominalism is of the radical kind I considered at the end of section 2. 
5. It is not an easy task to give an exact definition for what counts as an evolutionary explanation, but what I mean by this concept is quite broad: an evolutionary explanation is an explanation where the explanandum can be pretty much anything (although most of the time it is the apparent teleology of a property), but the explanans is an evolutionary process. Evolutionary processes, in turn, are defined conjunctively to include selection, founding effect, etc.

6. To give an example of a property-type that is considered to be a good candidate for a property that all and only members of a species have in all possible worlds: the property of being a member of a population with such and such distinctive evolutionary history (Griffiths 1999; Okasha 2002; the idea, again, comes from the anti-essentialist Matthen 1998). But everything this property-type can explain can be explained by individual-level processes, such as the specific evolutionary history of a specific organism, without appealing to any trait-types.

7. Richard Boyd argued that we can give an even weaker formulation of essentialism than the one we have considered so far. More precisely, essentialism does not necessarily imply that all and only the members of a natural kind must have a kind-specific essence. According to his "homeostatic property cluster theory," the members of a kind share a cluster of similar properties, but no property is necessary for membership in this kind (Boyd 1999). Boyd's "homeostatic property cluster theory" is quite complex and I do not intend to give a definitive argument against it. But we may be able to use the considerations above to make the following conditional claim. Boyd explicitly states that "the homeostatic clustering of properties . . . is causally important" $(1999,143)$. If this is to be understood in such a way that it is also explanatorily relevant, and if the "homeostatic clustering of properties" is supposed to be understood as a type that can have a number of different token instantiations, then Boyd's view contradicts the considerations I presented above in favor of the claim that property-types play no role in biological explanations.

\section{References}

Ariew, A. 2008. Population thinking. In Oxford Handbook of Philosophy of Biology, ed. M. Ruse. Oxford: Oxford University Press.

Armstrong, D. M. 1997. A World of States of Affairs. Cambridge: Cambridge University Press.

Boyd, R. 1999. Homeostasis, species, and higher taxa. In Species: New Interdisciplinary Essays, ed. R. Wilson. Cambridge, Mass.: MIT Press.

Campbell, K. 1981. The metaphysics of abstract particulars. Midwest Studies in Philosophy 6:477-488. Reprinted in Properties, ed. D. H. Mellor and A. Oliver. Oxford: Oxford University Press, 1997. 
Campbell, K. 1990. Abstract Particulars. Oxford: Blackwell.

Cummins, R. 1975. Functional analysis. Journal of Philosophy 72:741-765.

Daly, C. 1997. Tropes. In Properties, ed. D. H. Mellor and A. Oliver. Oxford: Oxford University Press.

Darwin, C. 1859. On the Origin of Species. Cambridge, Mass.: Harvard University Press.

Davidson, D. 1967. Causal relation. Journal of Philosophy 64: 691-703. Reprinted in D. Davidson, Essays on Actions and Events. Oxford: Clarendon Press, 1980.

Davidson, D. 1970. Mental events. In Experience and Theory, ed. L. Foster and J. Swanson. Amherst: University of Massachusetts Press. Reprinted in D. Davidson, Essays on Actions and Events. Oxford: Clarendon Press, 1980.

Davidson, D. 1993. Thinking causes. In Mental Causation, ed. J. Heil and A. Mele. Oxford: Oxford University Press.

Dawkins, R. 1982. The Extended Phenotype. Oxford: W. H. Freeman.

Devitt, M. 2008. Resurrecting biological essentialism. Philosophy of Science 75: 344-382.

Dretske, F. 1988. Explaining Behavior. Cambridge, Mass.: MIT Press.

Dretske, F. 1990. Reply to reviewers. Philosophy and Phenomenological Research 50:819-839.

Dupré, J. 1993. The Disunity of Science: Metaphysical Foundation of the Disunity of Science. Cambridge, Mass.: Harvard University Press.

Dupré, J. 2002. Humans and Other Animals. Oxford: Oxford University Press.

Ehring, D. 1997. Causation and Persistence: A Theory of Causation. Oxford: Oxford University Press.

Elder, C. L. 1995. A different kind of natural kind. Australasian Journal of Philosophy 73:516-531.

Ellis, B. 2001. Scientific Essentialism. Cambridge: Cambridge University Press.

Ereshefsky, M. 1998. Species pluralism and anti-realism. Philosophy of Science 65:103-120.

Ereshefsky, M. 2007. Species. In The Stanford Encyclopedia of Philosophy, ed. E. Zalta. Fall 2007 edition. <http://plato.stanford.edu/>.

Ereshefsky, M. Forthcoming. Natural kinds in biology. Routledge Encyclopedia of Philosophy.

Ereshefsky, M. Manuscript. What's wrong with the new biological essentialism? 
Ghiselin, M. T. 1974. A radical solution to the species problem. Systematic Zoology 23:536-544.

Godfrey-Smith, P. 2009. Darwinian Populations and Natural Selection. Oxford: Oxford University Press.

Griffiths, P. 1999. Squaring the circle: Natural kinds with historical essences. In Species: New Interdisciplinary Essays, ed. R. Wilson. Cambridge, Mass.: MIT Press.

Hacking, I. 2007. Natural kinds: Rosy dawn, scholastic twilight. In The Philosophy of Science, Royal Institute of Philosophy Supplements, vol. 61, ed. A. O'Hear. Cambridge: Cambridge University Press.

Hawthorne, J., and T. S. Gendler. 2000. Origin essentialism: The arguments reconsidered. Mind 109:285-298.

Hull, D. 1965. The effect of essentialism on taxonomy: 2000 years of stasis. British Journal for the Philosophy of Science 15:314-326; 16:1-18.

Hull, D. 1978. A matter of individuality. Philosophy of Science 45:335-360.

Hull, D. 1981. Units of evolution: A metaphysical essay. In The Philosophy of Evolution, ed. U. J. Jensen and R. Harré. Brighton: Harvester Press.

Hull, D. 1986. On human nature. PSA: Proceedings of the Biannual Meetings of the Philosophy of Science Association 2:3-13.

Hull, D. 1994. Contemporary systematic philosophies. In Conceptual Issues in Evolutionary Biology, 2nd ed., ed. E. Sober. Cambridge, Mass.: MIT Press.

Hull, D. L. 2001. Science and Selection. Cambridge: Cambridge University Press.

Hull, D. L., R. E. Langman, and S. S. Glenn. 2001. A general account of selection: Biology, immunology, and behavior. Behavioral and Brain Sciences 24:511-528. Reprinted in Hull 2001.

Kitcher, P. 2007. Does 'race' have a future? Philosophy \& Public Affairs 35:293317.

Kripke, S. 1980. Naming and Necessity. Cambridge, Mass.: Harvard University Press. Lewens, T. 2001. Sex and selection: Reply to Matthen. British Journal for the Philosophy of Science 52:589-598.

Matthen, M. 1998. Biological universals and the nature of fear. Journal of Philosophy 95:105-132.

Matthen, M. 1999. Evolution, Wisconsin style: Selection and the explanation of individual traits. British Journal for the Philosophy of Science 50:143-150.

Matthen, M. 2003. Is sex really necessary? And other questions for Lewens. British Journal for the Philosophy of Science 54:297-308. 
Mayr, E. 1942. Systematics and the Origin of Species. New York: Columbia University Press.

Mayr, E. 1959. Typological versus population thinking. In Evolution and Anthropology, ed. B. J. Meggers. Washington: The Anthropological Society of America. Reprinted in Conceptual Issues in Evolutionary Biology, ed. E. Sober. Cambridge, Mass.: MIT Press, 1994.

Mayr, E. 1963. Animal Species and Evolution. Cambridge, Mass.: Harvard University Press.

Mayr, E. 1969. The biological meaning of species. Biological Journal of the Linnean Society. Linnean Society of London 1:311-320. Reprinted in E. Mayr, Evolution and the Diversity of Life. Cambridge, Mass.: Harvard University Press, 1976.

Mayr, E. 1982. The Growth of Biological Thought: Diversity, Evolution, and Inheritance. Cambridge, Mass.: Harvard University Press.

Mayr, E. 1988. The ontology of the species taxon. In Towards a New Philosophy of Biology. Cambridge, Mass.: Harvard University Press.

Mayr, E. 1996. What is a species, and what is not? Philosophy of Science 63:262-277.

Mellor, D. H. 1995. The Facts of Causation. London: Routledge.

Millikan, R. G. 1990. Seismograph readings for "explaining behavior." Philosophy and Phenomenological Research 50:819-839.

Millikan, R. G. 1999. Historical kinds and the "special sciences." Philosophical Studies 95:45-65.

Nanay, B. 2005. Can cumulative selection explain adaptation? Philosophy of Science 72:1099-1112.

Nanay, B. 2009. The properties of singular causation. Monist 92:113-135.

Nanay, B. 2010a. Population thinking as trope nominalism. Synthese 177:91-109.

Nanay, B. 2010b. Natural selection and the limitations of environmental resources. Studies in History and Philosophy of Biological and Biomedical Sciences 41:418-419.

Nanay, B. 2011. What if reality has no architecture? Monist 94:181-197.

Neander, K. 1995a. Pruning the tree of life. British Journal for the Philosophy of Science 46:59-80.

Neander, K. 1995b. Explaining complex adaptations. A reply to Sober's "Reply to Neander." British Journal for the Philosophy of Science 46:583-587.

Okasha, S. 2002. Darwinian metaphysics: Species and the question of essentialism. Synthese 131:191-213. 
Oliver, A. 1996. The metaphysics of properties. Mind 105:1-80.

Platts, M. 1983. Explanatory kinds. British Journal for the Philosophy of Science 34:133-148.

Pust, J. 2001. Natural selection explanation and origin essentialism. Canadian Journal of Philosophy 31:201-220.

Putnam, H. 1975. Mind, Language, and Reality. Cambridge: Cambridge University Press.

Robb, D. 1997. The properties of mental causation. Philosophical Quarterly 47:178-194.

Robertson, T. 1998. Possibilities and the arguments for origin essentialism. Mind 107:729-749.

Rosenberg, A. 1983. Coefficients, effects, and genic selection. Philosophy of Science 50:332-338.

Sanford, D. H. Manuscript. Tropiary for beginners: Commentary on Peter Simons's "Particulars in Particular Clothing."

Schaffer, J. 2001. The individuation of tropes. Australasian Journal of Philosophy 79:247-257.

Simons, P. 1994. Particulars in particular clothing. Philosophy and Phenomenological Research 54:553-575.

Smith, B., and A. C. Varzi. 2001. Environmental metaphysics. In Metaphysics in the Post-Metaphysical Age, ed. U. Meixner. Vienna: Hölder-Pichler-Tempsky.

Smith, B., and A. C. Varzi. 2002. Surrounding space: On the ontology of organismenvironment relations. Theory in Biosciences 120:139-162.

Sober, E. 1980. Evolution, population thinking, and essentialism. Philosophy of Science 47:350-383.

Sober, E. 1981. Evolutionary theory and the ontological status of properties. Philosophical Studies 40:147-176.

Sober, E. 1984. The Nature of Selection. Cambridge, Mass.: MIT Press.

Sober, E. 1995. Natural selection and distributive explanation. British Journal for the Philosophy of Science 46:384-397.

Sober, E., and R. Lewontin. 1982. Artifact, cause, and genic selection. Philosophy of Science 49:157-180.

Sober, E., and R. Lewontin. 1983. Reply to Rosenberg on genic selection. Philosophy of Science 50:648-650. 
Stegmann, U. 2010. What can natural selection explain? Studies in History and Philosophy of Biological and Biomedical Sciences 41:61-66.

van Fraassen, B. 1980. The Scientific Image. Oxford: Oxford University Press.

Walsh, D. M. 1998. The scope of selection: Sober and Neander on what natural selection explains. Australasian Journal of Philosophy 76:250-264.

Walsh, D. M. 2006. Evolutionary essentialism. British Journal for the Philosophy of Science 57:425-448.

Walsh, D. M., T. Lewens, and A. Ariew. 2002. The trials of life: Natural selection and random drift. Philosophy of Science 69:429-446.

Wilkerson, T. E. 1995. Natural Kinds. Aldershot: Avebury.

Williams, D. C. 1953. On the elements of being. Review of Metaphysics 7:3-18, 171-192.

Wilson, R. A. 1999. Realism, essence, and kind: Resuscitating species essentialism? In Species: New Interdisciplinary Essays, ed. R. A. Wilson. Cambridge, Mass.: MIT Press.

Wilson, R. A., M. J. Barker, and I. Brigandt. Forthcoming. When traditional essentialism fails: Biological natural kinds. Philosophical Topics.

Wimsatt, W. C. 1980. Units of selection and the structure of the multi-level genome. Philosophy of Science Association 2:122-193.

Wolterstorff, N. 1973. On Universals. Chicago: University of Chicago Press. 
